\title{
O Tratado de Cooperação Amazônica e a Conferência das NaÇões UNIDAS SOBRE DESENVOLVIMENTO SUSTENTÁVEL
}

The Amazon Cooperation Treaty and the United Nations Conference on sustainable development

\section{Guilherme Henrich Benek Vieira}

Professor universitário. Mestrando do Programa de Pós-Graduação em Direito Ambiental da Universidade do Estado do Amazonas (UEA). Membro do Centro de Estudos em Direito Ambiental da Amazônia (CEDAM). Bolsista CAPES. E-mail:gbenek@hotmail.com.

\section{Priscila Silva De Souza}

Mestranda do Programa de Pós-Graduação em Direito Ambiental da Universidade do Estado do Amazonas (UEA). Membro do Centro de Estudos em Direito Ambiental da Amazônia (CEDAM). E-mail: ms.priscila@hotmail.com

\section{Resumo}

A sociedade tem testemunhado um longo debate em face da questão ambiental e das mudanças climáticas. Isso se dá, em grande parte, pela rapidez com que observamos os fenômenos naturais assolarem todas as partes do mundo com suas catástrofes. A culpa por tantas mazelas enfrentadas nos últimos cento e cinquenta anos é imputada à sociedade capitalista que, a partir da Revolução Industrial, se arvorou dos recursos naturais sem se preocupar 
com as consequências que a sociedade global teria que enfrentar pelo uso imoderado da natureza. O desenvolvimento econômico mundial, expressado em valores no Produto Interno Bruto de cada país, não tem considerado na produção dos seus bens e serviços o custo social, cultural e ambiental. Surge, então, no cenário mundial uma tensão econômica entre aqueles que esgotaram os seus recursos naturais e alcançaram o desenvolvimento a qualquer custo contra aqueles ainda com recursos, mas sem desenvolvimento. A preocupação com o meio ambiente no cenário internacional aumentou a partir da década de 60 , quando estudos alertavam sobre os riscos à vida humana, de animais e plantas pela degradação do meio ambiente em favor do crescimento econômico imoderado. Esses estudos formaram a base das discussões dessa década e início da seguinte, desembocando na Conferência das Nações Unidas sobre o Meio Ambiente Humano, no ano de 1972, em Estocolmo. Na esteira mundial da preocupação com o meio ambiente, Bolívia, Brasil, Colômbia, Equador, Guiana, Peru, Suriname e Venezuela, reconhecendo a importância que tem para cada um dos países as suas respectivas regiões amazônicas, assinaram em 1978 o Tratado de Cooperação Amazônica (TCA). Em 2012, as Nações Unidas se reuniram em uma nova Conferência no Rio de Janeiro com o objetivo de renovar o compromisso político com o desenvolvimento sustentável. Sendo importante analisar o papel da Amazônia e do TCA nessas discussões.

Palavras-chave: Tratado de Cooperação Amazônica. Direito Ambiental Internacional. ConferênCia das NaÇões Unidas. Estocolmo 72. Rio +20 .

\section{Abstract}

The society has witnessed a long debate in the face of environmental issues and climate change. This occurs in large part by the speed with which we observe natural phenomena that destroyed all over the world with its disasters. The blame for many ills faced in the last hundred and fifty years is attributed to the capitalist society that, from the Industrial Revolution, was hoisted natural resources without worrying about the consequences that global society would face the immoderate use of nature. The world economic development, values expressed in the GDP of each country, has seen the production of their goods and services cost the social, cultural and environmental. Then it comes a strain on the world scene economically among those who have exhausted their natural resources and the development achieved at any cost even against those with resources, but without development. Concern for the environment in the international arena has increased from the 60's, when studies warned about the risks to human life, animals and plants for the degradation of the 
environment in favor of economic growth immoderate. These studies formed the basis of discussions that decade and early next, resulting in the United Nations Conference on the Human Environment in 1972 in Stockholm. In the wake of the global concern for the environment, Bolivia, Brazil, Colombia, Ecuador, Guyana, Peru, Suriname and Venezuela, recognizing the importance for each country their respective Amazonian regions, in 1978 signed the Amazon Cooperation Treaty (TCA). In 2012, the United Nations gathered at a new conference in Rio de Janeiro in order to renew political commitment to sustainable development. While it is important to analyze the role of the Amazon and the TCA in these discussions.

Keywords: Amazon Cooperation Treaty. International Environmental Law. United Nations Conference. Stockholm 72. Rio +20.

Sumário: Introdução. 1. O Direito Ambiental Internacional. 2. O Tratado de Cooperação Amazônica (TCA). 3. A Conferência das Nações Unidas sobre o desenvolvimento sustentável e o Tratado de Cooperação Amazônica. Conclusão. Referências.

\section{INTRODUÇÃo}

Hodiernamente a sociedade tem se debruçado sobre o debate acerca da urgência da preservação do meio ambiente e dos efeitos das mudanças climáticas. Esses debates são ocasionados, principalmente, pela quantidade de desastres naturais que ocorreram no mundo todo.

Tem-se imputado ao Homem, e ao seu modo de viver, baseado no capitalismo e no uso irracional dos recursos naturais, a culpa por tantas mazelas enfrentadas nos últimos cento e cinquenta anos, posto que, a partir da Revolução Industrial, a sociedade capitalista se arvorou dos recursos naturais sem se preocupar com as consequências que toda a sociedade global teria que enfrentar pelo uso imoderado da natureza.

Assim, os conflitos surgidos a partir dessa corrida por recursos naturais fazem com que a cada dia o meio ambiente não consiga se recuperar. O nível de poluição encontra-se muito maior do que a natureza consegue receber e reciclar.

O desenvolvimento econômico mundial, expressado em valores no Produto Interno Bruto de cada país, não tem considerado na produção dos seus bens e serviços o custo social, cultural e ambiental (FONSECA, 2011, p. 427). 
Esse pensamento divide o mundo em países desenvolvidos e subdesenvolvidos, levando os subdesenvolvidos a correr atrás do desenvolvimento sem considerar os impactos dessa empreitada.

Surge, então, no cenário mundial uma tensão econômica entre aqueles que esgotaram os seus recursos naturais e alcançaram o desenvolvimento a qualquer custo contra aqueles ainda com recursos, mas sem desenvolvimento. Essa é uma discussão carregada de simbolismos e de políticas, pois muitos países em desenvolvimento acusam os países desenvolvidos de utilizarem o discurso de proteção do meio ambiente para impedir o crescimento econômico daqueles países, tendo em vista que alcançaram a prosperidade utilizando todos ou quase todos os seus recursos naturais.

Alheios a essa discussão ideológica, pois não caberia neste espaço discutila, cumpre-nos analisar o seu impacto para a preservação do meio ambiente e quais os meios que alguns Estados têm utilizados para garantir a preservação da natureza e a não poluição dos recursos além dos seus territórios.

Sendo a Floresta Amazônica a maior floresta tropical do mundo, ocupando quase dois terços do território brasileiro (59\%), segundo dados do IBGE (2012), estendendo-se a outros países sul-americanos, caracterizando como uma floresta transnacional. Destarte, é importante analisarmos como os Estados que a detêm a protegem.

Nesse sentido, oportuna é a análise do Tratado de Cooperação Amazônica, pois este visa coordenar as ações dos países membros com vistas a preservar a Floresta Amazônica por meio de cooperação técnica e científica transnacional.

Sendo assim, torna-se imperiosa a investigação da seguinte questão: qual o posicionamento do Estado brasileiro no que concerne ao referido Tratado e qual a sua importância nas discussões da Conferência das Nações Unidas sobre Desenvolvimento Sustentável realizada na cidade do Rio de Janeiro em 2012?

Assim, muito embora o bioma Amazônico constitua quase dois terços do território brasileiro e abrigue a maior floresta tropical do mundo, a falsa ideia de que por ser muito nunca acaba, tem feito com que a preservação da floresta tenha sido relegada para segundo plano, ainda que se tenha um Tratado com vistas a viabilizar a cooperação técnica e científica entre os países da região amazônica.

O Tratado de Cooperação Amazônica, assim como outros tratados e convenções, é tido como soft law, não gerando para os membros que o descumprirem nenhuma sanção, o que, por vezes, dá a ideia de uma carta de intenções e não de compromisso assumido entre os seus signatários.

Contudo, a presente pesquisa não buscará analisar como todos os países membros do Tratado o tem implementado, mas sim como o Brasil se relacionou com o tema durante a realização da importante Conferência das Nações Unidas realizada no Brasil em 2012. 


\section{O DIREITO AMBIENTAL INTERNACIONAL}

O meio ambiente está presente nas atividades do homem desde sempre. O ser humano com a sua capacidade de transformação evoluiu com a utilização dos recursos naturais. A história da civilização nos mostra a intrínseca relação do homem com a natureza, contudo essa relação sempre foi de domínio e exploração do primeiro sobre o segundo.

Saleme (2004, p. 201) pontua que:

A presença do Estado como ente que dá a proteção ao indivíduo foi tema de amplo debate entre filósofos e juristas envolvidos no processo de democratização dos autoritários estados do passado. No entanto, quando a civilização iniciou seu processo de descaso ao meio ambiente, pouco se falou da ingerência do Estado para proteger esses recursos escassos e finitos.

Entretanto, nos últimos anos, temos visto o recrudescimento da importância do meio ambiente e dos seus recursos para a manutenção da vida humana.

Essa preocupação com o meio ambiente, segundo Silva (2009, p. 27), deuse, em um primeiro momento, "em razão de sua utilidade para os seres humanos, quer dizer, o objetivo primordial era a proteção de interesses econômicos", como é o caso da Convenção de Paris para a proteção do pássaros úteis à agricultura de 1902, lembra a autora. A proteção é direcionada ao ambiente de um Estado.

Contudo, o simples fato de proteger os recursos de determinado Estado não foi suficiente para garantir a estabilidade do meio ambiente, tendo em vista que cada um escolhe a forma e o mecanismo de proteção ambiental.

Isso levou alguns países a reclamarem da falta de instrumentos capazes de impedir que a degradação do meio ambiente em um país afete outro país vizinho, a chamada poluição transfronteiriça. Assim, a comunidade internacional buscou modos de tentar combater esse tipo de poluição, pois, como salienta Fiorillo (2011, p. 129):

Não há como pensar no meio ambiente dissociado dos demais aspectos da sociedade, de modo que ele exige uma atuação globalizada e solidária, até mesmo porque fenômenos como a poluição e a degradação ambiental não encontram fronteiras e não esbarram em limites territoriais.

Silva $(2009$, p. 18) aponta que a preocupação com o meio ambiente aumentou a partir do estudo feito por Raquel Carson, na década de 60, alertando sobre os riscos à saúde humana, de animais e plantas pela utilização de DDT, pondo em xeque a utilização da tecnologia, aparentemente inofensiva, mas causadora de sérios danos ao homem e ao meio ambiente. 
Afirma ainda Prieur (in HARTMANN, 2009, p. 32) que:

O direito ambiental é a expressão formal de uma nova política surgida a partir dos anos 1960. Trata-se de uma conscientização do caráter limitado (finito) dos recursos naturais e também dos efeitos nefastos das poluições de todo o tipo, resultante da produção de bens e de seu consumo.

Esses estudos, assim como outros, formaram a base das discussões do final da década de sessenta e início da década de setenta e irá desembocar no Encontro sobre o clima e o meio ambiente da Organização das Nações Unidas (ONU) em 1972 em Estocolmo.

Saleme (2004, p. 203) acrescenta:

A degradação do meio ambiente passou a ser tema que não saía das pautas de diversas reuniões internacionais; várias entidades foram cometidas de novas responsabilidades no âmbito ambiental, como a elaboração de legislação própria, entre outras ações necessárias à contenção de atos de violação do equilíbrio ambiental.

Essas discussões são "o gérmen de uma série de medidas propostas pelos mais diversos organismos internacionais que formam as bases do que se denominou, mais tarde, Direito Ambiental Internacional" (SALEME, 2004, p. 203).

Assim:

$\mathrm{O}$ direito ambiental internacional refere-se às normas de direito internacional destinadas a realizar a proteção e gestão do meio ambiente, quer dizer, refere-se a uma perspectiva de análise do direito internacional sob o prisma ambiental ao tratar dos direitos e obrigações dos Estados, dos organizações internacionais, bem como dos indivíduos na defesa do meio ambiente (SILVA, 2009, p. 7) (destaque no original).

Feito essas breves considerações acerca do surgimento da preocupação com a preservação do meio ambiente no cenário mundial, nossa pesquisa tem o escopo de perquirir de que forma esse entendimento se reflete na proteção da Amazônia, tendo em vista o seu caráter transnacional, mormente haver sido celebrado pelo Brasil e os outros países da Amazônia um Tratado com vistas a proteger a floresta e os seus recursos. 


\section{O Tratado de Cooperação Amazônica (TCA)}

Primeiramente, cumpre definir o que seria um Tratado e como ocorre a sua recepção na ordem jurídica brasileira.

A Convenção de Viena sobre o Direito dos Tratados de 1969, aprovado pelo Congresso Nacional por meio do Decreto Legislativo n. 496, de 17 de julho de 2009 , com reservas aos artigos 25 e 66, define o tratado como "acordo internacional concluído por escrito entre Estados e regido pelo Direito Internacional, quer conste de um instrumento único, quer de dois ou mais instrumentos conexos, qualquer que seja sua denominação específica" (art. $2^{\circ}, 1^{\circ}$, letra a).

Segundo Husek (2000, p. 50):

Tratado é o acordo formal concluído entre os sujeitos de Direito Internacional Público destinado a produzir efeitos jurídicos na órbita internacional.

É a manifestação de vontade de tais entes. Um ato jurídico formal que envolve pelo menos duas vontades.

Moraes (1998, p. 299) conceitua tratado internacional como "o acordo de dois ou mais sujeitos da comunidade internacional que se destina a produzir determinados efeitos jurídicos".

Rezek afirma:

A produção de efeitos de direito é essencial ao tratado, que não pode ser visto senão na sua dupla qualidade de ato jurídico e de norma. $\mathrm{O}$ acordo formal entre Estados é o ato jurídico que produz a norma, e que, justamente por produzi-la, desencadeia efeitos de direito, gera obrigações e prerrogativas, caracteriza enfim, na plenitude de seus dois elementos, o tratado internacional $(2010$, p. 18).

Destarte, os tratados internacionais consistem em fonte de obrigação do Direito Internacional que obriga seus signatários, uma vez que devem ser expressão de consenso, não devendo ser oriundo de imposição.

Em regra geral, a negociação, conclusão e assinatura de um tratado competem ao chefe de Estado.

No Brasil, o processo de negociação da assinatura até a promulgação do tratado na ordem interna compreende três etapas distintas: 
1- compete privativamente ao Presidente da República celebrar tratados, convenções e atos internacionais (art. 84, VII da CF);

2- compete exclusivamente ao Congresso Nacional (art. 49, I da CF) resolver definitivamente sobre tratados, acordos ou atos internacionais que fará por meio de decreto legislativo, o qual deverá ser promulgado pelo Presidente da República.

3- o tratado internacional para produzir efeitos na ordem interna e adquirir executoriedade, deve ser promulgado através de um decreto presidencial (com força de lei), passando então a "vincular e obrigar no plano no plano do direito positivo interno" como lei ordinária (STF, ADIn n. 1.480-3/DF, DJ 18/05/2001).

Moraes (1998, p. 299/301) considera que, por ingressar com status infraconstitucional no ordenamento jurídico brasileiro, eventual conflito deverá ser dirimido pela utilização do critério cronológico ou do princípio da especialidade.

Exceção ao status de lei ordinária ocorre com os tratados e convenções internacionais sobre direitos humanos aprovados, em cada Casa do Congresso Nacional, em dois turnos, por três quintos dos votos dos respectivos membros, sendo equivalentes às emendas constitucionais por força do que dispõe o $\S 3^{\circ}$ do art. $5^{\circ}$ da Constituição.

A Amazônia é uma floresta latifoliada úmida que cobre a maior parte da Bacia Amazônica da América do Sul. Esta bacia abrange sete milhões de quilômetros quadrados, dos quais cinco milhões e meio de quilômetros quadrados são cobertos pela floresta tropical. Esta região inclui territórios pertencentes a nove nações. A maioria das florestas está contida dentro do Brasil, com $60 \%$ da floresta, seguido pelo Peru com 13\% e com pequenas quantidades na Colômbia, Venezuela, Equador, Bolívia, Guiana, Suriname e França (Guiana Francesa). A Amazônia representa mais da metade das florestas tropicais remanescentes no planeta e compreende a mais biodiversa de floresta tropical do mundo.

No Brasil, para efeitos de governo e economia, a Amazônia é delimitada por uma área chamada “Amazônia Legal” definida pela Lei n. 5.173/66. É chamado também de Amazônia o bioma que, no Brasil, ocupa 59,1\% do território e abrange três (Norte, Nordeste e Centro-Oeste) das cinco divisões regionais do país, sendo o maior bioma do país (IBGE, 2012).

Toda essa grandiosidade faz do Brasil o país mais importante para a preservação da Amazônia, contudo, devemos lembrar que compõem a Amazônia outros oito países (Bolívia, Colômbia, Equador, França (Guiana Francesa), Guiana, Peru, Suriname e Venezuela). 
Sendo assim, as Repúblicas da Bolívia, do Brasil, da Colômbia, do Equador, da Guiana, do Peru, do Suriname e da Venezuela, reconhecendo a importância que tem para cada um dos países as suas respectivas regiões amazônicas como parte integrante do seu território, assinaram no dia 3 de julho de 1978, na cidade de Brasília, o Tratado de Cooperação Amazônica (TCA), onde os membros firmaram o propósito de:

Realizar esforços e ações conjuntas a fim de promover o desenvolvimento harmônico de seus respectivos territórios amazônicos, de modo a que essas ações conjuntas produzam resultados equitativos e mutuamente proveitosos, assim como para a preservação do meio ambiente e a conservação e utilização racional dos recursos naturais desses territórios (OTCA, 2012).

Insta observar que a Guiana Francesa não assinou o Tratado por se tratar de uma colônia, e por isso não teria soberania para ser defendida no tratado.

“Assim, para alcançar o desenvolvimento sustentável da região, ou seja, um desenvolvimento pautado nos pilares da viabilidade econômica, prudência ecológica e justiça social, há a necessidade da adoção de instrumentos de gestão ambiental" (SOLA et al, 2012, p. 1) e que para uma área tão extensa é necessário um esforço conjunto dos vários países da região.

Freire afirma que "perante essas demandas é mais fácil partilhar com outros Estados a resolução de problemas que são comuns a todos eles" (2012). Contudo, ainda que o Tratado tenha sido assinado em 1978 e entrado em vigor em 03 de agosto de 1980, trinta dias após o depósito de ratificação da Venezuela (LINS, 2010, p. 305), Fonseca aponta que:

Ficou nas gavetas ministeriais de vários governos até que [...] entre 1995 e 1998, o documento foi resgatado e recolocado em discussão pelos países membros. Depois de vários encontros preliminares, em 14 de dezembro de 1998, foi realizada, em Caracas (Venezuela), uma reunião das nações signatárias, ocasião em que foi assinado um protocolo de emenda destinado, segundo o texto original, "a aperfeiçoar e fortalecer, institucionalmente, o processo de cooperação desenvolvido sob a égide do mencionado instrumento" (2011, p. 42).

A preocupação mundial com o desenvolvimento sustentável, bem como a importância que a região tem para a humanidade, faz da OTCA um instrumento contemporâneo para a sustentabilidade global e um espaço concreto para a 
cooperação entre as nações e, em um contexto mais amplo, contribui para o fortalecimento das relações internacionais, à luz de sua especial singularidade amazônica, demonstrando quão certos estavam os governos ao tomarem a decisão de revitalizar o Tratado de Cooperação Amazônica (OTCA, 2012).

Sendo o Tratado de Cooperação Amazônica uma espécie de guia de procedimentos, de diretrizes e princípios, um instrumento normativo onde não são previstas sanções, sua importância encontra-se no fato prever direitos e obrigações aos signatários e por se constituir um dos poucos costumes internacionais relacionado ao meio ambiente (FREIRE et al, 2012, p. 15), tornando relevante a pesquisa do tratamento dispensado ao tema durante a realização da Conferência das Nações Unidas sobre o Desenvolvimento Sustentável.

\section{A Conferência das NaÇões Unidas sobre o desenvolvimento sustentável e o Tratado de Cooperação Amazônica}

Como dito alhures, a preocupação com o meio ambiente no cenário internacional recrudesceu na década de 60 com o acontecimento de grandes catástrofes ambientais, bem como com a publicação de estudos alertando sobre o perigo de crescimento econômico sem a observância dos problemas da poluição e do esgotamento dos recursos.

Assim, no ano de 1972, em Estocolmo na Suécia, foi realizada a Conferência das Nações Unidas sobre o Meio Ambiente Humano. A Conferência foi, até então, a maior já realizada, contou com a representação de 113 países e mais de 400 organizações não governamentais, embora somente dois chefes de Estado tenham comparecido: Olaf Palme (Suécia) Indira Gandhi (Índia).

A Conferência exerceu um importante papel na formação do Direito Ambiental Internacional, reconhecendo a urgência em preservar o meio ambiente e de um agir por parte dos Estados para a consecução desse objetivo.

Ao término da Conferência foram produzidos dois documentos: a Declaração das Nações Unidas sobre o Meio Ambiente Humano e o Plano de Ação para o Meio Ambiente. A Declaração trata da necessidade da adoção de um critério e de princípios que ofereçam aos povos inspiração e guia para preservar e melhorar o meio ambiente em âmbito nacional e internacional. O Plano é composto por 109 recomendações que tratam da avaliação dos problemas ambientais, da gestão do meio ambiente, identificando os diversos problemas, e das medidas de apoio com vistas à informação e à educação ambiental.

Foi sugerida ainda a criação do Programa das Nações Unidas para o Meio Ambiente (PNUMA), formalizada pela Resolução n. 2.997 da Assembleia Geral das Nações Unidas do dia 15 de dezembro de 1972, e recomendado à 
Assembleia a realização de uma segunda Conferência sobre o Meio Ambiente Humano (SILVA, 2009, p. 28-31).

No ano de 1992, vinte anos após a Conferência de Estocolmo, foi realizada a Conferência das Nações Unidas sobre Meio Ambiente e Desenvolvimento na cidade do Rio de Janeiro, como um resultado do Relatório Brundtland que:

Afirmava a necessidade de entrar em uma nova era de crescimento econômico apoiado em práticas que conservassem e expandissem a base dos recursos naturais [...] em 1988, a Assembleia das Nações Unidas aprovou a Resolução 43/196 que estabelecia que a conferência sobre temas ambientais deveria ser realizada até o ano de 1992 [...] por consenso, foi então adotada a Resolução 44/228 da Assembleia Geral das Nações Unidas aos 22 de dezembro de 1989 sobre a realização da Conferência das Nações Unidas sobre o Meio Ambiente e Desenvolvimento no Rio de Janeiro com duração de duas semanas e coincidindo com o dia do meio ambiente -5 de junho. (SILVA, 2009, p. 32s)

Para a Conferência de 1992, o Brasil adota posicionamento diverso da Conferência de 1972. Segundo Boeira (2012, p. 530), isto se deu por quatro fatores:

a) crise simbólica do modelo desenvolvimentista (economicista e predatório); b) sensibilização do governo em relação aos problemas ambientais, em razão da soberania sobre $2 / 3$ da maior floresta pluvial do mundo, sobre a qual a comunidade internacional exigia uma reavaliação; c) existência de uma matriz energética brasileira baseada em recursos naturais renováveis (hidroelétrica e biomassa) num contexto em que a quase totalidade dos países é dependente de combustíveis fósseis ou de energia nuclear; d) pressão por um compromisso globalista, já que o Brasil era o anfitrião da Conferência.

A Conferência do Rio-92 reuniu 178 países e mais de 100 chefes de Estado, além de mais de oito mil delegados, organizações intergovernamentais, organizações não governamentais e jornalistas. Como resultado da Conferência, três documentos foram aprovados, a Declaração do Rio, a Agenda 21 e a Declaração sobre Florestas, e duas Convenções foram abertas à assinatura, a Convenção-Quadro das Nações Unidas sobre Mudança do Clima e a Convenção das Nações Unidas sobre Diversidade Biológica (SILVA, 2009, p. 35).

Silva afirma que, ainda que a Conferência tenha deixado questões pendentes, ela foi a primeira a estabelecer uma obrigação de avaliação dos progressos realizados do seu plano de ação cinco anos mais tarde. O resultado 
da avaliação realizada em Nova Iorque em 1997, nas palavras do presidente da conferência, foi decepcionante, devido a falta de meios financeiros e das relações econômicas que continuavam a desprezar a variável ambiental (SILVA, 2009, p. 39).

As Nações Unidas decidiram realizar, em 2002, na África do Sul, uma Conferência para marcar os dez anos da Rio-92, analisar os resultados alcançados e indicar o caminho a ser seguido para implementação dos compromissos. A Cúpula Mundial sobre Desenvolvimento Sustentável reuniu, em Johanesburgo, mais de 100 Chefes de Estado e reafirmou metas relativas à erradicação da pobreza, à promoção da saúde, à expansão dos serviços de água e saneamento, à defesa da biodiversidade e à destinação de resíduos tóxicos e não tóxicos.

A agenda de debates incluiu energias renováveis e responsabilidade ambiental das empresas, bem como a necessidade de que todos os atores sociais somem esforços na promoção do desenvolvimento sustentável.

Em 2012, a Conferência das Nações Unidas sobre Desenvolvimento Sustentável foi realizada na cidade do Rio de Janeiro. É também conhecida como Rio+20 porque marcaram os vinte anos de realização da Conferência das Nações Unidas sobre Meio Ambiente e Desenvolvimento (Rio-92).

A Conferência teve como objetivo renovar o compromisso político com o desenvolvimento sustentável, por meio da avaliação do progresso e das lacunas na implementação das decisões adotadas por outras cúpulas realizadas sobre o assunto e para tratar de novos temas.

A Conferência teve dois temas principais: a economia verde no contexto do desenvolvimento sustentável e da erradicação da pobreza e a estrutura institucional para o desenvolvimento sustentável.

Sobre o tema economia verde no contexto do desenvolvimento sustentável e da erradicação da pobreza, o desafio proposto à comunidade internacional é o de pensar um novo modelo de desenvolvimento que seja ambientalmente responsável, socialmente justo e economicamente viável. Assim, a economia verde pode ser uma ferramenta para o desenvolvimento sustentável. No Brasil o debate sobre o tema encontra-se em estágio inicial.

No que se refere ao tema da estrutura institucional para o desenvolvimento sustentável, insere-se a discussão sobre a necessidade de fortalecimento do multilateralismo como instrumento para solução dos problemas globais. Buscase aumentar a coerência na atuação das instituições internacionais relacionadas aos pilares social, ambiental e econômico do desenvolvimento.

Nesse contexto, vários eventos paralelos foram realizados para discutir a temática ambiental relacionada aos objetivos de discussão da Conferência.

No dia 20 de junho de 2012, os países membros da OTCA se reuniram para apresentarem sua visão sobre o desenvolvimento sustentável, em especial 
no manejo florestal sustentável e para apresentar os progressos na efetivação do projeto: Monitoramento do Desmatamento na Mata Panamazônica.

No dia 21 de junho de 2012, a Comissão de Relações Exteriores e Defesa Nacional, do Senado, e a Comissão Mista sobre Mudanças Climáticas, composta de senadores e deputados, reuniram-se com o Vice-Ministro das Relações Exteriores do Suriname, Robby Ramlakhan; o secretário-geral da OTCA, embaixador Alejandro A. Gordillo; o chefe da missão diplomática do Equador no Brasil e presidente da Comissão de Coordenação do Conselho de Cooperação Amazônica, embaixador Horacio Sevilla Borja; e o representante do Fórum Brasileiro de Mudanças Climáticas, professor Marcos Aurélio de Freitas Vasconcelos, para discutir formas de aprofundar o Tratado de Cooperação Amazônica, assinado em 1978.

\section{Conclusão}

Segundo a Câmara dos Deputados (BRASIL, 2012a), o foco de reunião realizada pela Comissão Mista paralelamente à Conferência das Nações Unidas foi o controle do desmatamento e o desenvolvimento da Amazônia.

Para o representante do Fórum Brasileiro, não é todo desmatador que é bandido, muitas vezes trata-se de cidadão em busca de fonte de renda, sugerindo a adoção de políticas que visem explorar o potencial da floresta sem prejudicar o meio ambiente, mas que traga renda aos povos da região. Defendeu ainda o pagamento de royalties aos povos indígenas pela construção de hidrelétricas em suas terras.

Para a presidente da Comissão de Relações Exteriores e de Defesa Nacional da Câmara, Perpétua Almeida (AC), é preciso investir na Amazônia, garantindo renda, emprego e capacitação para quem preserva a floresta. Segundo o deputado Padre Ton (RO), parlamentares dos países amazônicos aproveitaram a Rio+20 para discutir políticas de preservação da floresta, com inclusão social e erradicação da pobreza na região.

A audiência pública debateu a atuação da OTCA, a aprovação do financiamento do Banco Nacional de Desenvolvimento Econômico e Social (BNDES) para o projeto de monitoramento do desmatamento e das mudanças de uso da terra na Amazônia e a criação de uma universidade com foco no desenvolvimento sustentável e que é preciso aumentar o monitoramento e os recursos para a região.

De acordo com a vice-presidente da comissão mista, senadora Vanessa Grazziotin (AM), o BNDES poderá financiar projetos em toda a região amazônica e não apenas no Brasil. Para a senadora, o “objetivo é chegar em 2013, em abril, na Conferência Mundial das Nações Unidas sobre Florestas 
levando um mapa sobre desmatamento não só da Amazônia brasileira, mas da Amazônia global, incluindo todos os oito países" (BRASIL, 2012a).

O secretário-geral da OTCA, embaixador Alejandro Gordillo, que participou da audiência pública, disse que a organização tem como meta hoje implantar o projeto para monitorar o desmatamento e recuperar a cobertura florestal da região, o que demanda intensa cooperação entre os oito países-membros.

O embaixador lembrou ainda que a OTCA foi uma das primeiras organizações internacionais a citarem o termo desenvolvimento sustentável como um de seus objetivos estratégicos, com vistas ao equilíbrio entre crescimento econômico e preservação ambiental.

Contudo, a Amazônia abriga mais de 40 mil espécies de plantas e 10 mil de animais, a discussão sobre a efetiva implementação do Tratado, da defesa e desenvolvimento da região Amazônica restringe-se a conclusão de que "é preciso aumentar", "é preciso investir", "é preciso criar" etc.

A Amazônia desperta o interesse do mundo não só pela sua exuberante beleza natural, mas principalmente pelo seu incalculável valor econômico. A preocupação internacional com o meio ambiente tem o seu marco com a Conferência de 72 e, entre outros fatores, o fato do Brasil ser um dos países citados no relatório Nosso Futuro Comum com catastróficos índices de degradação ambiental, dimensão continental e por possuir a maior floresta tropical do planeta, o fizeram ser escolhido para sediar a Conferência de 92 (CAPOBIANCO, 2012).

Passados quarenta anos de uma e vinte da outra, os planos de desenvolvimento para a Amazônia continuam nos discursos do que devemos fazer, mas pouco ou nada têm sido feito de concreto por ela. É de conhecimento comum o seu tamanho, sua beleza e seu valor.

Inúmeras reuniões, convenções, conferências debatem a urgência em reunir esforços para mapeá-la com o fim de proteger o patrimônio natural e preservar os conhecimentos tradicionais da floresta, mas pouco ou nada podem fazer se não houver vontade política para tal desiderato.

A Conferência da Rio+20, e seus inúmeros eventos paralelos, discutiram a questão do meio ambiente nas suas mais diferentes perspectivas, contudo a sensação é de nada foi feito. É preciso encarar com seriedade a questão amazônica, é necessário que saiamos do discurso e passemos para a prática.

Aventa-se a criação de uma universidade, mas quando será criada? Por que não investir desde já em pesquisa na região? Por que não estreitar as relações com os países amazônicos para trocar informações?

Vemos com pesar que o discurso supera em muito a ação, aproveita-se esses momentos de mídia para ladrar possíveis atitudes, mas passados esses momentos, volta-se ao estado de letargia e de profunda inação. 
A questão da preservação e do desenvolvimento da Amazônia passa indiscutivelmente pela realização de reuniões para definir o plano de trabalho, mas é preciso avançar, é preciso realizar o planejado. E, num primeiro momento, vê-se que o Tratado de Cooperação Amazônica só entrou no discurso do que é preciso fazer, criar ou planejar, mas a mais de trinta anos não sai deste estágio e ainda não foi com a realização da Conferência das Nações Unidas sobre o Desenvolvimento Sustentável que se avançará para a efetivação do Tratado.

É preciso avançar na discussão sobre os meios de implantar a cooperação entre os Estados que compõem o acordo com o objetivo de fazer com que os investimentos caminhem juntos com a inclusão social, geração de emprego, saneamento básico, moradia, com dignidade e desenvolvimento para a região. 


\section{REFERÊNCIAS}

BOEIRA, Sérgio Luís. Politica e gestão ambiental no Brasil: da Rio-92 ao Estatuto da Cidade. Disponível em: http://www6.univali.br/seer/index.php/ra/ article/viewFile/ 1840/1465. Acessado em: 22.07.2012.

BRASIL. Câmara dos Deputados. Disponível em: http://www2.camara. gov.br/ agencia/noticias/MEIO-AMBIENTE/420648-CONTROLE-DODESMATAMENTO-E-FOC O-DE-AUDIENCIA-DE-COMISSAO-DOCONGRESSO.html. Acessado em: 20.07.2012.

BRASIL. Constituição da República Federativa do Brasil de 1988. Disponível em: http://www.planalto.gov.br/ccivil_03/constituicao/ConstituicaoCompilado. htm. Acessado em: 31.08.2012.

BRASIL. Decreto Legislativo n. 496, de 17 de julho de 2009. Disponível em: http://www.planalto.gov.br/ccivil_03/_Ato2007-2010/2009/Decreto/D7030.htm. Acessado em: 31.08.2012.

BRASIL. Decreto n. 7.030, de 14 de dezembro de 2009. Disponível em: http:// www.planalto.gov.br/ccivil_03/_Ato2007-2010/2009/Decreto/D7030.htm. Acessado em: 31.08.2012.

BRASIL. Instituto Brasileiro de Geografia e Estatística. Disponível em: http http://www.ibge.gov.br/home/geociencias/geografia/mapas_doc5.shtm. Acesadso em: 23.07.2012.

CAPOBIANCO, João Paulo. O que podemos esperar da Rio-92? Disponível em: http://www.seade.gov.br/produtos/spp/v06n01-02/v06n01-02_03.pdf. Acessado em: 02.07. 2012.

FIORILlO, Celso Antonio Pacheco. Curso de Direito Ambiental Brasileiro. São Paulo: Saraiva, 2011.

FONSECA, Ozório José de Menezes. Pensando a Amazônia. Manaus: Valer, 2011.

FREIRE, Cristiniana Cavalcanti; TORQUATO, Carla Cristina Alves; COSTA, José Augusto Fontoura. Juridificação internacional: análise do Tratado de Cooperação Amazônica em face dos desafios ambientais internacionais. Disponível em: http://www.conpedi.org.br/ manaus/arquivos/anais/manaus/direito_ambiental_ cristiniana_cavalcanti_freire_e_outros.pdf. Acessado em: 18.07.2012. 
HARTMANN, Analúcia de Andrade. Políticas públicas ambientais: a atuação do Ministério Público. In: D’ISEP, Clarissa Ferreira Macedo; NERY JÚNIOR, Nelson; MEDAUAR, Odete (Coord.). Políticas públicas ambientais: estudos em homenagem ao professor Michel Prieur. São Paulo: Revista dos Tribunais, 2009.

HUSEK, Carlos Roberto. Curso de Direito Internacional Público. 3. ed. São Paulo: LTr, 2000.

LINS, Diogo de Oliveira. A efetividade do Tratado de Cooperação Amazônica como tratado-quadro de proteção ambiental da fauna e da flora do Brasil. In Revista de Direito Ambiental da Amazônia. Ano 7-8, n. 13-14. Manaus: UEA, 2010.

MORAES, Alexandre de. Direitos humanos fundamentais: teoria geral, comentários aos artigos $1^{\circ}$ ao $5^{\circ}$ da Constituição da República Federativa do Brasil, doutrina e jurisprudência. São Paulo: Atlas, 1998.

OTCA. Organização do Tratado de Cooperação Amazônica. Disponível em: http://www.otca.info/portal/admin/_upload/tratado/O_TRATADO_DE_ COOPERACAO_AMAZONICA_PT.pdf. Acessado em: 13.06.2012.

OTCA. Plano estratégico 2004-2012. Disponível em: http://www.otca.info/ portal/ admin/_upload/plano_estrategico/Plano_Estrategico2004-2012.pdf. Acessado em 19.07.2012.

RESEK, Francisco. Curso elementar de Direito Internacional Público. 12. ed. 2 tiragem. São Paulo: Saraiva, 2010.

SALEME, Edson Ricardo. Normas e políticas públicas no Direito Ambiental Internacional. In Revista de Direito Ambiental da Amazônia. Ano 2, n. 2. Manaus: UEA, 2004.

SILVA, Solange Teles da. O Direito Ambiental Internacional. Belo Horizonte: Del Rey, 2009. Coleção para entender.

SOLA, Fernanda; COSTA Luís Carlos; SILVA, Solange Teles da; COSTA, José Augusto Fontoura. Responsabilidade civil ambiental nos países integrantes do Tratado de Cooperação Amazônica. Disponível em: http://www.conpedi.org. br/manaus/arquivos/anais/manaus/direito_ambiental_fernanda_sola_e_outros. pdf. Acessado em: 09.06.2012. 